\title{
Occipitocervical synostosis: case report
}

\author{
Buse Kayhan $^{1}$, Pelin İlhan', Mete Ertürk², Gülgün Şengül ${ }^{2}$ \\ ${ }^{1}$ Department of Neuroscience, Ege University Institute of Health Sciences, Izmir, Turkey \\ ${ }^{2}$ Department of Anatomy, Ege University Faculty of Medicine, İzmir, Turkey
}

\begin{abstract}
Fusion of atlas with the occipital bone is a rare congenital anomaly known as occipitocervical synostosis, occipitalization of atlas, assimilation of atlas or atlanto-occipital fusion. We describe two cases of occipitocervical synostosis identified amongst one-hundred dry adult human occipital bones from the collection of Ege University, School of Medicine, Department of Anatomy (incidence $0.5 \%$ ). The synostosis was complete type for both cases. Occipitocervical synostosis is clinically important as it may cause narrowing of foramen magnum which may compress the brainstem, vertebral artery and cranial nerves, and during surgical approaches to the craniovertebral region.
\end{abstract}

Keywords: atlanto-occipital fusion; occipital bone; occipitalization of atlas; occipitocervical synostosis

Anatomy 2015;9(2):104-107 @2015 Turkish Society of Anatomy and Clinical Anatomy (TSACA)

\section{Introduction}

Synostosis or fusion of atlas with occipital bone is a rare congenital malformation at the craniovertebral junction known as occipitocervical synostosis, occipitalization of the atlas, or atlanto-occipital fusion, ${ }^{[1]}$ first described by Rokitansky in $1884 .{ }^{[2]}$ During the first week of intrauterine life, the atlas partially or totally fuses with the occipital bone due to failure in segmentation and separation of the most caudal occipital sclerotome and the first cervical sclerotome. ${ }^{[3]}$ Occipitocervical synostosis may be associated with other skeletal malformations such as spina bifida of atlas, occipital vertebra, basilar invagination, Klippel-Feil syndrome (fusion of the second and third cervical vertebrae), Arnold-Chiari I malformation and cervical stenosis. ${ }^{[4]}$ Patients with occipitocervical synostosis do not develop symptoms until the second decade of life.

Occipitocervical synostosis is usually asymptomatic, incidentally found during radiological and operative procedures or during autopsy. When present, symptoms vary from simple headache to a full-blown neurological syndrome, and develop gradually with aging due to an increase in ligamentous laxity and instability. ${ }^{[5]}$ Neurological complications can be due to compression of the spinal cord, spinal nerves and vessels, causing occipital headache, neck pain, numbness and pain in the limbs, weakness and abnormal head posture. ${ }^{[-8]}$ Cranial nerve compression may lead to tinnitus, visual disturbances, and lower cranial nerve palsies leading to dysphagia and dysarthria. ${ }^{[8]}$

Anomalies in the craniovertebral junction area are important due to the localization of the vertebral artery and first cervical nerve on the superior aspect of the atlas. Compression of the vertebral artery can cause a decrease in the brain blood flow; similarly, compression of the first cervical nerve can cause neurological symptoms. ${ }^{[9]}$

Arnold-Chiari I syndrome is a downward displacement of the cerebellar tonsils through the foramen magnum (the opening at the base of the skull; FM) due to the obstruction of cerebrospinal fluid outflow. Similar to occipitocervical synostosis, this also leads to a compression of the spinal cord, spinal nerves and vessels, making the neurological symptoms and signs for both indistinct. ${ }^{[1,11]}$ Patients with occipitocervical synostosis can have the tonic-clonic seizures observed in Arnold-Chiari $\mathrm{I}^{[8,10]}$ Occipitocervical synostosis has also been reported in animals such as the horse, dog and sheep. ${ }^{[12-14]}$

Occipitocervical synostosis can be complete or incomplete (partial). In the complete type, there is complete fusion of the atlas with the occipital bone, whereas in the incomplete type there are osseous bridges between the atlas and the occipital bone. Complete synostosis is 

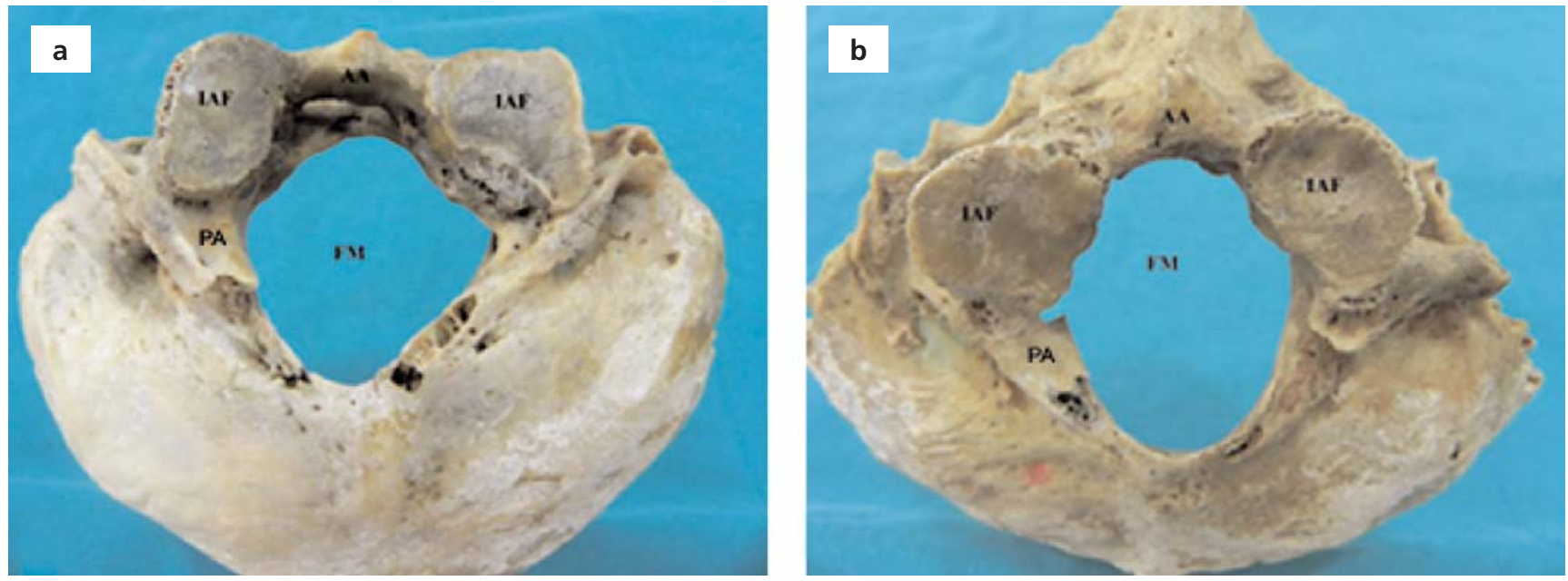

Figure 1. (a, b) Complete occipitocervical synostosis, Case 1 and 2. The posterior arches of the atlas were broken on the left and right sides. AA: anterior arch; FM: foramen magnum; IAF: inferior articular facet; PA: posterior arch.

more common than the partial one. Multiple variations of incomplete occipitocervical synostosis may involve the atlanto-occipital joint. In this study, we describe two cases of complete occipitocervical synostosis.

\section{Case Report}

During morphometric analysis of one hundred dry human adult skulls from the collection of Ege University School of Medicine, Department of Anatomy, two occipitocervical synostosis cases were identified (incidence $0.5 \%$ ); the occipitalization was complete for both cases. Asymmetry was observed in the size of the inferior articular facet (IAF) of the atlas. The left side of the IAF had a protrusion in both cases (Figures 1a and b). A cleft was observed between the anterior arch of the atlas and the occipital bone (Figure 1a).

The sagittal (anteroposterior) and transverse diameters of the FM and IAF were measured using a digital caliper. The sagittal and transverse diameters of FM were $35.7 \pm 0.26 \mathrm{~mm}$ and $30.32 \pm 2.65 \mathrm{~mm}$, respectively for the first case, and $35.3 \pm 0.26$ and $26.56 \pm 2.65 \mathrm{~mm}$, respectively for the second case. The transverse diameter of the IAFs were $16.5 \pm 1.88$ and $13.84 \pm 1.88 \mathrm{~mm}$ on the right side, and
$11.48 \pm 1.35$ and $13.40 \pm 1.35 \mathrm{~mm}$ on the left side. The sagittal diameter was $22.97 \pm 1.26$ and $21.18 \pm 1.26 \mathrm{~mm}$ on the right side, and $19.64 \pm 0.37$ and $19.11 \pm 0.37 \mathrm{~mm}$ on the left side (Table 1). Hypoglossal canals were observed on both sides for the two cases.

\section{Discussion}

Occipitocervical synostosis ranges from complete incorporation of the atlas into the occiput to discrete osseous bridges between the two. ${ }^{[15]}$ Tubbs et al. ${ }^{[16]}$ stated that occipitocervical synostosis is normally congenital, but in rare cases it may be a result of osteomyelitis, arthritis, syphilis or tuberculosis.

The incidence of occipitocervical synostosis has been reported as $0.67 \%$ by Jadhav et al., ${ }^{[5]} 1 \%$ by Mudaliar et al. ${ }^{[1]} 2 \%$ by Nimje and Wankhede, ${ }^{[17]} 3.63 \%$ by Kassim et al. ${ }^{[18]}$ and $2 \%$ by Gopal et al. ${ }^{[19]}$ In our study, the incidence is $0.5 \%$. Gopal et al. ${ }^{[19]}$ observed 20 cases with occipitocervical synostosis. In all their cases, superior articular facets were fused with the occipital condyles. Partial fusion (left half) of anterior arch of atlas with the basal part of occipital bone was found in one specimen (5\%) and in $10 \%$ there was complete fusion. In two (10\%) skulls the poste-

Table 1

Transverse and sagittal diameters of foramen magnum and inferior articular facets (mm).

\begin{tabular}{|c|c|c|c|c|c|c|}
\hline \multirow[t]{2}{*}{ Case } & \multirow{2}{*}{$\begin{array}{c}\text { Sagittal diameter } \\
\text { of FM }\end{array}$} & \multirow{2}{*}{$\begin{array}{c}\text { Transverse diameter } \\
\text { of FM }\end{array}$} & \multicolumn{2}{|c|}{ Transverse diameter of IAF } & \multicolumn{2}{|c|}{ Sagittal diameter of IAF } \\
\hline & & & Right & Left & Right & Left \\
\hline 1 & 35.7 & 30.32 & 16.5 & 11.4 & 22.97 & 19.64 \\
\hline 2 & 35.33 & 26.56 & 13.84 & 13.4 & 21.18 & 19.11 \\
\hline
\end{tabular}


rior arch fused with the occipital bone. Bilateral fusion of the transverse process with occipital bone was noted in two $(10 \%)$ specimens. Bilateral incomplete foramen transversarium was found in one skull (5\%), and in 2 skulls $(10 \%)$ the transverse process was noted without the foramen transversarium bilaterally.

Mudaliar et al. ${ }^{[1]}$ classified four types of occipitocervical synostosis based on the zones of atlas fused with occiput: Zone 1 with fusion of the anterior arch of atlas in front of the lateral masses (20\% in their series), Zone 2 with fusion involving primarily the lateral processes $(17 \%)$, Zone 3 with fusion involving the posterior arch of atlas behind the lateral masses (13\%), and Zone 4 as combinations of all zones $(50 \%)$. In majority of cases, the fusion is between the anterior arch of the atlas and the anterior margin of FM. In this study, the two cases belonged to the category of Zone 4 in Mudalier's classification. Nayak et al..$^{[20]}$ described a skull in which the lateral masses of the atlas were fused completely with the occipital condyles, and the anterior arch was fused with the basilar part of the occipital bone. The hypoglossal canals were absent. As in our case, a cleft was found between the anterior arch of the atlas and the basilar part of the occipital bone. The posterior arch fused with the squama of the occipital bone with some perforations. The vertebral artery passage to the cranial cavity was very narrow.

Jayanthi et al. ${ }^{[12]}$ reported two cases of occipitocervical synostosis with spina bifida of atlas. In the first case, there was a complete fusion of only one of the lateral masses of the atlas with the occipital bone and the anterior arch fused incompletely. In the second case, the anterior arch of the atlas fused with the occipital bone. The second case was with unilateral fusion of the lateral mass with the occipital bone along with the partial anterior arch fusion with the basilar part of occipital bone in one skull and complete anterior arch fusion in other. ${ }^{[12]}$

Caspersen et al. ${ }^{[2]}$ stated that occipitocervical synostosis may be associated with a small FM and deviant shape of the posterior cranial fossa. Craniofacial morphology in the vertical and sagittal dimensions including the cranial base is normal in skulls with occipitocervical synostosis. This indicates that occipitalization is associated with the surrounding bone structures and not with deviations in craniofacial morphology.

Bose and Shrivastava ${ }^{[22]}$ presented a rare case of incomplete fusion of the atlanto-occipital joint. In their case, there was partial fusion of the incomplete bony ring of the atlas to the base of occipital bone. Important findings included a narrowing of foramen magnum, total fusion of lateral masses, anterior and posterior arches being partially fused on the left side, completely fused on the right side, a divided foramen found on the right side possibly for the vertebral artery and the first cervical nerve. The IAFs were asymmetric with different sizes.

Occipitocervical synostosis is clinically important as it may cause narrowing of FM which may compress the brainstem, vertebral artery and cranial nerves, and lead to difficulties during surgical approaches to the craniovertebral region. A variety of symptoms occur such as cervical pain and convulsions. ${ }^{[12,23-27]}$ Vakili et al. ${ }^{[28]}$ reported a sudden death case due to occipitocervical synostosis. In neurological examination of occipitocervical synostosis, the patient may show clinical symptoms such as headache, neck pain, numbness and pain in the limbs, weakness, abnormal head posture, posteriorly located dull aching headache. According to McRae and Barnum, ${ }^{[2]}$ patients with occipitocervical synostosis may have physical features such as low hairline, torticollis, restricted neck movements and /or abnormal short neck.

Iwata et al. ${ }^{[30]}$ reported a case of atlanto-occipital fusion with unusual neurological symptoms. His patient had atlanto-occipital occipitalization accompanied with atlanto-axial instability causing anterior shifting of the atlas during certain movements. His neurological symptoms resembled those caused by tumors in the region of FM. They concluded that the symptoms resulted from myelomalacia caused by discontinuous compression of the spinal cord by the posterior edge of the assimilated atlas. They observed worsening of the symptoms with slight neck extension and maximal mouth opening.

\section{Conclusion}

Occipitocervical synostosis is clinically significant as it may cause narrowing of foramen magnum which may compress the brainstem, vertebral artery and cranial nerves. It should be noted that this pathology may cause a wide range of clinical features, and neurosurgeons, orthopedic surgeons, radiologists and anesthesiologists should be aware during their interventions.

\section{References}

1. Mudaliar RP, Shetty S, Nanjundaiah K, Kumar JP, Kc J. An osteological study of occipitocervical synostosis: its embryological and clinical significance. J Clin Diagn Res 2013;7:1835-37.

2. Campos D, Silva TH, Ellwanger JH, Goerck ML, Kipper JF, Piazza JL, Kraether NL. Atlanto-occipital fusion and its neurological complications: a case report. Journal of Morphological Sciences 2012;29: $111-3$.

3. Guebert GM, Yochum TR, Rowe LJ. Congenital anomalies and normal skeletal variants. In: Yochum TR, Rowe LJ, editors. Essentials of skeletal radiology. Baltimore: Williams and Wilkins; 1987. p. 197-306. 
4. Saini V, Singh R, Bandopadhyay M, Tripathi SK, Shamal SN. Occipitalization of the atlas: Its occurrence and embryological basis. International Journal of Anatomical Variations 2009;2:85-8.

5. Jadhav SD, Ambali MP, Patil RJ, Doshi MA, Roy PP. Assimillation of atlas in Indian dry skulls. Journal of Krishna Institute of Medical Sciences University 2012;1:102-6.

6. Al-Motabagani MA, Surendra M. Total occipitalization of the atlas. Anat Sci Int 2006;81:173-80.

7. Taitz C. Bony observation of some morphological variation and anomalies of the cranio-vertebral region. Clin Anat 2000;13:354-60.

8. Lang J. Craniocervical region, osteology and articulation. Neuroorthopedics 1986;1:67-92.

9. Goel A, Sharma P, Dange N, Kulkami AG. Techniques in the treatment of craniovertebral instability. Neurol India 2005;53:525-33.

10. Bergman P. On varieties of atlas in man. Folio Morphologica (Warsaw) 1967;26:129-39.

11. Smith CA, Tuan RS. Human PAX gene expression and development of vertebral column. Clin Orthop Relat Res 1994;(302):241-50.

12. Jayanthi V, Kulkarni R, Kulkarni RN. Atlanto-occipital fusion report of two cases. J Anat Soc India 2003;52:71-3.

13. Mayhew IG, Watson AG, Heissan JA. Congenital occipitoatlantoaxial malformations in the horse. Equine Vet J 1978;10:103-13.

14. Van Nie CJ, Folkerts JF. Occipitalization of the atlas in a sheep [proceedings]. Acta Morphol Neerl Scand 1977;15:325.

15. Pang D, Thompson DN. Embryology and bony malformations of the craniovertebral junction. Review. Childs Nerv Syst 2011;27:523-64.

16. Tubbs RS, Salter EG, Oakes WJ. The intracranial entrance of the atlantal segment of the vertebral artery in crania with occipitalization of the atlas. J Neurosurg Spine 2006;4:319-22.

17. Nimje DA, Wankhede HA. Atlanto-occipital fusion: a rare anomaly of the craniocervical junction. Edorium Journal of Anatomy and Embryology 2014;1:1-4.

18. Kassim NM, Latiff AA, Das S, Ghafar NA, Suhaimi FH, Othman F, Hussan F, Sulaiman IM. Atlanto-occipital fusion: an osteological study with clinical implications. Bratisl Lek Listy 2010;111:562-5.
19. Gopal K, Choudhary AK, Agarwal J, Ali S. Morphological status of assimilated atlas vertebra with occipital bone and its clinical significance. International Journal of Research in Medical Sciences 2015;3: $420-42$.

20. Nayak S, Vollala VR, Raghunathan D. Total fusion of atlas with occipital bone: a case report. Neuroanatomy 2005;4:39-40.

21. Caspersen LM, Kjaer I, Sonnesen L. How does occipitalization influence the dimensions of the cranium? Orthod Craniofac Res 2010;13:162-8.

22. Bose A, Shrivastava S. Partial occipitalization of atlas. International Journal of Anatomical Variations 2013;6:81-4.

23. Lopez ZA, Limousin LA, Mantz JR. Contribution to the classification of malformations of the atlas in the light of a new unstable malformation (3 cases). [Article in Spanish] Revista Clínica Española 1964;94:208-15.

24. Budin E, Sondheimer F. Lateral spread of the atlas without fracture. Radiology 1966;87:1095-8.

25. Albrecht HJ, Castrischer E. Fission formation in the anterior and posterior atlas arch. [Article in German] Fortschr Geb Rontgenstr Nuklearmed 1968;108:543-5.

26. Childers JC, Wilson FC. Bipartite atlas. J Bone Joint Surg Am 1971; 53:578-582.

27. Keller HL. Variations in form and abnormalities of the atlas and its surrounding area. [Article in German] Fortschr Geb Rontgenstr Nuklearmed 1961;95:361-70.

28. Vakili ST, Aguilar JC, Muller J. Sudden unexpected death associated with atlanto-occipital fusion. Am J Forensic Med Pathol 1985;6:39-43.

29. McRae DL, Barnum AS. Occipitalization of the atlas. Am J Roentgenol Radium Ther Nucl Med 1953;70:23-46.

30. Iwata A, Murata M, Nukina N, Kanazawa I. Foramen magnum syndrome caused by atlanto-occipital assimilation. J Neurol Sci 1998; 154:229-31.

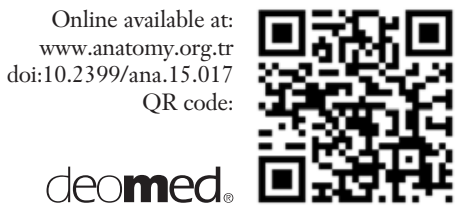

Correspondence to: Mete Ertürk, MD

Department of Anatomy, Faculty of Medicine,

Ege University, 35100 , Izmir, Turley

Phone: +90 2323903985

e-mail: erturkmete68@gmail.com

Conflict of interest statement: No conflicts declared.

This is an open access article distributed under the terms of the Creative Commons Attribution-NonCommercial-NoDerivs 3.0 Unported (CC BY-NCND3.0) Licence (http://creativecommons.org/licenses/by-nc-nd/3.0/) which permits unrestricted noncommercial use, distribution, and reproduction in any medium, provided the original work is properly cited. Please cite this article as: Kayhan B, İlhan P, Ertürk M, Şengül G. Occipitocervical synostosis: case report. Anatomy 2015;9(2):104-107. 